\title{
Investigating Surface Effects on Thermomechanical Behavior of Embedded Circular Curved Nanosize Beams
}

\author{
Farzad Ebrahimi and Mohsen Daman \\ Department of Mechanical Engineering, Faculty of Engineering, Imam Khomeini International University, Qazvin, Iran \\ Correspondence should be addressed to Farzad Ebrahimi; febrahimy@eng.ikiu.ac.ir
}

Received 26 May 2016; Accepted 28 July 2016

Academic Editor: Parviz Malekzadeh

Copyright (C) 2016 F. Ebrahimi and M. Daman. This is an open access article distributed under the Creative Commons Attribution License, which permits unrestricted use, distribution, and reproduction in any medium, provided the original work is properly cited.

\begin{abstract}
To investigate the surface effects on thermomechanical vibration and buckling of embedded circular curved nanosize beams, nonlocal elasticity model is used in combination with surface properties including surface elasticity, surface tension, and surface density for modeling the nanoscale effect. The governing equations are determined via the energy method. Analytically Navier method is utilized to solve the governing equations for simply supported nanobeam at both ends. Solving these equations enables us to estimate the natural frequency and critical buckling load for circular curved nanobeam including Winkler and Pasternak elastic foundations and under the effect of a uniform temperature change. The results determined are verified by comparing the results with available ones in literature. The effects of various parameters such as nonlocal parameter, surface properties, Winkler and Pasternak elastic foundations, temperature, and opening angle of circular curved nanobeam on the natural frequency and critical buckling load are successfully studied. The results reveal that the natural frequency and critical buckling load of circular curved nanobeam are significantly influenced by these effects.
\end{abstract}

\section{Introduction}

Nanomaterials are attracting many researchers over the recent years due to their improvement of the quality properties. Atomistic modeling and experimental researches show that the size effect gains important when the dimensions of structures become very small. Due to this fact, the size effect plays an important role on the mechanical behavior of microand nanostructures [1]. Among various nanostructures, nanobeams have more important applications $[2,3]$. Reddy [4] has investigated nonlocal theories for bending, buckling, and vibration of beams. Moreover, Demir and Civalek [5] have surveyed torsional and longitudinal vibration and wave response of microtubules based on the nonlocal continuum and nonlocal discrete theories. Meanwhile a nonlocal beam theory is presented by Thai [6], in this research; bending, buckling, and vibration of nanobeams have been investigated. However, the nonlinear vibration of the piezoelectric nanobeams based on the Timoshenko beam theory and nonlocal modeling has been investigated by Ke et al. [7]. In addition Murmu and Adhikari [8] have investigated the nonlocal transverse vibration of double-nanobeam-system.
In this research, an analytical method has been developed for determining the natural frequencies of the nonlocal doublenanobeam-system. Also Eltaher et al. [9] have presented free vibration analysis of functionally graded (FG) size-dependent nanobeams using finite element method.

Because the nanobeams has the high proportion of the surface to volume, the surface stress effects have important role in their mechanics behavior of these structures. The effect of the residual surface stress on the beam gives the distributed loading on the two surfaces. Hence Gurtin and Murdoch [10] have considered surface stress effects. In this theory the surface is considered as a part of (nonphysical) the two-dimensional body with zero thickness (mathematically) which has covered the total volume. This theory has been used in many researches about nanostructures [11-14]. Nonlinear free vibration of functionally graded nanobeams with surface effects has been investigated by Sharabiani and Yazdi [15]. Furthermore, the nonlinear free vibration of nanobeams with considering surface properties has been studied by Nazemnezhad et al. [16]. However, Hosseini-Hashemi and Nazemnezhad [17] have presented nonlinear free vibration of 
functionally graded nanoscale beams with surface properties. Also, Ansari et al. [18] have investigated nonlinear forced vibration characteristics of nanobeams including surface stress effect. In this study, a new formulation of the Timoshenko beam theory has been developed through the GurtinMurdoch elasticity theory in which the effect of surface stress has been incorporated. Moreover, the surface and nonlocal effects on the nonlinear flexural free vibrations of elastically supported nonuniform cross-section nanobeams have been investigated by Malekzadeh and Shojaee [19] simultaneously. In addition, Ebrahimi et al. [20] have presented surface and nonlocal effects on buckling and vibrational analysis of nanotubes with various boundary conditions.

In the field of elastic foundation there are linear and nonlinear ones which are called Winkler and Pasternak, respectively. Zhao et al. [21] have investigated the axial buckling of a nanowire resting on Winkler-Pasternak substrate medium with the Timoshenko beam theory. In addition, simple analytical expressions have been presented by Fallah and Aghdam [22] for large amplitude free vibration and postbuckling analysis of functionally graded beams rest on nonlinear elastic foundation. Furthermore, Jang et al. [23] have presented a new method of analyzing the nonlinear deflection behavior of an infinite beam on a nonlinear elastic foundation. Also, Niknam and Aghdam [24] have obtained a closed form solution for both natural frequency and buckling load of nonlocal functionally graded beams resting on nonlinear elastic foundation. Moreover, the static instability of a nanobeam with geometrical imperfections with elastic foundation has been investigated by Mohammadi et al. [25]. In this paper, size-dependent effect is included in the nonlinear model. Nevertheless, differential transformation method has been used to predict the buckling behavior of single walled carbon nanotube on Winkler foundation under various boundary conditions by Pradhan and Reddy [26].

In recent years vibrations of curved nanobeams and nanorings have been done in many empirical experiments and dynamic molecular simulations [27]. Hence some researchers are interested in studying of vibration curved nanobeams and nanorings. Malekzadeh et al. [28] have presented outof-plane free vibration of functionally graded circular curved beams in thermal environment. However, Yan and Jiang [29] have investigated the electromechanical response of a curved piezoelectric nanobeam with the consideration of surface effects. In addition, a new numerical technique, the differential quadrature method, has been developed for dynamic analysis of the nanobeams in the polar coordinate system by Kananipour et al. [30]. Moreover, Khater et al. [31] have investigated the effect of surface energy and thermal loading on the static stability of nanowires. In this research, nanowires have been considered as curved fixed-fixed EulerBernoulli beams and have used Gurtin-Murdoch theory to represent surface effects. The model has taken into account both von Kármán strain and axial strain. Also, Wang and Duan [27] have surveyed the free vibration problem of nanorings/arches. In this research the problem was formulated on the framework of nonlocal elasticity theory. Furthermore, DQ thermal buckling analysis of embedded curved carbon nanotubes via nonlocal elasticity model has been presented by Setoodeh et al. [32]. Nevertheless, explicit solution has been shown for size- and geometry-dependent free vibration of curved nanobeams including surface effects by Assadi and Farshi [33].

Recently, nanostructures have generated a great deal of interest from research. These distinguished properties make them apt for potential applications in nanoelectromechanical systems (NEMS) such as nanosensors $[34,35]$ and nanoactuators [36].

Ebrahimi and Salari [37] presented a semianalytical method for vibrational and buckling analysis of FG nanobeams considering the physical neutral axis position. Recently Ebrahimi and Barati [38-41] presented static and dynamic modeling of a thermopiezoelectrically actuated nanosize beam subjected to a magnetic field. Most recently small scale effects on hygrothermomechanical vibration of temperaturedependent nonhomogeneous nanoscale beams are investigated by Ebrahimi and Barati [42]. They [43] also proposed a nonlocal higher-order shear deformation beam theory for vibration analysis of size-dependent functionally graded nanobeams. The influences of various thermal environments on buckling and vibration of nonlocal temperaturedependent FG beams is analyzed by Ebrahimi and Salari [44] using Navier analytical solution. In another work, Ebrahimi and Salari [45] investigated thermomechanical vibration of FG nanobeams with arbitrary boundary conditions applying differential transform method. Also, Ebrahimi et al. [46] explored the effects of linear and nonlinear temperature distributions on vibration of FG nanobeams.

To the best of the author's knowledge, there is no study regarding the surface effects on thermomechanical vibration and buckling of embedded circular curved nanosize beams. Therefore, there is a strong scientific need to understand the thermomechanical vibration and buckling behavior of circular curved nanobeams with surface effects in considering the effect of elastic foundations. Curvature rather exists in all of the real beams and nanobeams. Moreover, in previous researches in order to streamline mathematical equations, straight beam models have been used, whilst curved beam models are more practicable than straight ones. Analyzing of the vibration treatment of nanostructures is an important topic in the design process of the nanodevices. The aim of this research is to survey the effects of temperature changes and Winkler and Pasternak elastic foundation on natural frequencies and critical buckling loads of curved nanobeams with and without surface properties. So the paper has investigated the effects of surface density, surface elasticity, and surface residual stress.

\section{Theories and Relations}

2.1. Displacement Fields. Consider a free vibration of curved nanobeam as is shown in Figure 1, with the radius curvature and thickness as $R$ and $h$, respectively. In addition surface properties are assumed for surface elasticity, surface tension, and surface density.

Based on the Timoshenko beam model, the displacement fields of an arbitrary point of the circular curved nanobeam can be defined as follows:

$$
\begin{aligned}
U(\theta, z, t) & =u(\theta, t)+z \varphi_{\theta}(\theta, t), \\
W(\theta, z, t) & =w(\theta, t),
\end{aligned}
$$




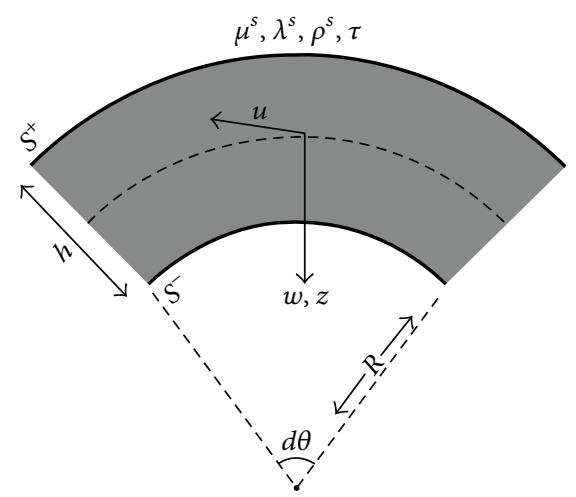

Figure 1: Geometry of an element of a circular curved nanobeam with surface layers.

where $u$ and $w$ give the middle displacements in $\theta$ and $z$ directions, respectively. $\varphi_{\theta}$ is the rotation of transverse normal.

The relation between length of circular curved beam $(\alpha)$ and the angle of curvature of beam $(\theta)$ can be written as [32]

$$
\alpha=R \theta .
$$

The normal and shear strains at any point of the beam space can be denoted as follows:

$$
\begin{aligned}
\varepsilon_{\theta} & =\frac{1}{(1+z / R)}\left(\varepsilon_{\theta}^{0}+z \chi_{\theta}\right), \\
\lambda_{\theta z} & =\frac{1}{(1+z / R)}\left(\gamma_{\theta z}^{0}\right),
\end{aligned}
$$

where $\varepsilon_{\theta}^{0}$ and $\gamma_{\theta z}^{0}$ are the normal and shear strains in the main surface. $\chi_{\theta}$ is the curvature change. They are explained in terms of the middle surface displacements and rotation as [36]

$$
\begin{aligned}
\varepsilon_{\theta}^{0} & =\frac{\partial u}{R \partial \theta}+\frac{w}{R} ; \\
\chi_{\theta} & =\frac{\partial \varphi_{\theta}}{R \partial \theta} ; \\
\lambda_{\theta z}^{0} & =\frac{\partial w}{R \partial \theta}-\frac{u}{R}+\varphi_{\theta} .
\end{aligned}
$$

By exerting the integration of the stresses with respect to the cross-section, the normal force and moment resultants can be determined as

$$
\begin{gathered}
{\left[\begin{array}{l}
N \\
Q
\end{array}\right]=b \int_{-h / 2}^{h / 2}\left[\begin{array}{c}
\sigma_{\theta} \\
\tau_{\theta z}
\end{array}\right] d z ;} \\
M=b \int_{-h / 2}^{h / 2} \sigma_{\theta} z d z,
\end{gathered}
$$

where $Q$ deputes the transverse shear force resultant.
2.2. Hamilton Principle. The strain energy $\left(U_{s}\right)$ of the circular curved nanobeams for free vibration analysis can be expressed as

$$
U_{s}=\frac{1}{2} \int_{\theta}\left\{N \varepsilon_{\theta}^{0}+M \chi_{\theta}+Q \gamma_{\theta z}^{0}\right\} R d \theta .
$$

Moreover, the kinetic energy $(T)$ of the circular curved nanobeam can be defined as [36]

$$
T=\frac{1}{2} \int_{\theta}\left\{\bar{I}_{0}\left(\frac{\partial u}{\partial t}\right)^{2}+\bar{I}_{0}\left(\frac{\partial w}{\partial t}\right)^{2}\right\} R d \theta
$$

where the inertia components are given as

$$
\begin{aligned}
\bar{I}_{0} & =I_{0}+\frac{I_{1}}{R}, \\
{\left[I_{0}, I_{1}\right] } & =b \int_{-h / 2}^{h / 2} \rho[1, z] d z,
\end{aligned}
$$

where $\rho$ is the density of the circular curved nanobeam. The work done corresponding to temperature changes and elastic foundations can be written in the following form [32]:

$$
W_{\mathrm{ext}}=\frac{1}{2} \int_{\theta}\left\{\frac{N^{T}}{R^{2}}\left(\frac{\partial w}{\partial \theta}\right)^{2}+f\right\} R d \theta
$$

\section{Mathematical Process}

The Lagrangian functional $(L)$ of the beams for free vibration analysis is demonstrated in terms of the energy expressions as

$$
L=T-U_{s}-W_{\text {ext }} \cdot
$$

By substituting (6)-(9) into (10) and employing the Hamilton's principle as (11), governing equation can be determined:

$$
\int_{0}^{t} \delta\left(T-U_{s}-W_{\text {ext }}\right) d t=0 .
$$

Equation (11) can be satisfied only if the coefficients of the virtual displacements are zero. Hence, motion equations of circular curved nanobeams with considering surface properties and elastic foundations are obtained as follows:

$$
\begin{aligned}
\frac{\partial N}{\partial \theta}+Q & =\left(\rho A R+2 b R \rho^{s}\right) \frac{\partial^{2} u}{\partial t^{2}}, \\
-N+\frac{\partial Q}{\partial \theta}-f R+\frac{N^{T}}{R} \frac{\partial^{2} w}{\partial \theta^{2}} & =\left(\rho A R+2 b R \rho^{s}\right) \frac{\partial^{2} w}{\partial t^{2}}, \\
\frac{\partial M}{\partial \theta}-Q R & =0,
\end{aligned}
$$

where $A, \rho$, and $\rho^{s}$ are the cross-sectional area, mass density, and surface density of the circular curved nanobeam, respectively. In (12) $b$ is the width of circular curved nanobeam.

Omitting the normal stress resultant $N$ from (12) obtains the relation between radial displacement and bending 
moment component. For this aim it is essential to differentiate the first of the two equations in (12) with respect to $\theta$ and then insert the obtained relation for $\partial N / \partial \theta$ into the other. Also by neglecting products of small quantities $\partial u / \partial \theta=-w$ [47], derivation of the obtained result with respect to $\theta$, and streamline, this relation determines

$$
\begin{aligned}
& \frac{1}{R}\left(\frac{\partial^{4} M}{\partial \theta^{4}}+\frac{\partial^{2} M}{\partial \theta^{2}}\right)+\frac{N^{T}}{R} \frac{\partial^{4} w}{\partial \theta^{4}}-\frac{\partial^{2} f}{\partial \theta^{2}} R \\
& \quad=\left(\rho A R+2 R b \rho^{s}\right)\left(\frac{\partial^{4} w}{\partial \theta^{2} \partial t^{2}}-\frac{\partial^{2} w}{\partial t^{2}}\right) .
\end{aligned}
$$

Then again, the constitutive equation of elastic surface materials for the general case is defined as [10]

$$
\begin{aligned}
\tau_{\alpha \beta}^{ \pm}= & \tau \delta_{\alpha \beta}+\left(\mu^{s}-\tau\right)\left(u_{\alpha \beta}^{ \pm}+u_{\beta \alpha}^{ \pm}\right)+\left(\lambda^{s}+\tau\right) u_{\gamma \gamma}^{ \pm} \delta_{\alpha \beta} \\
& +\tau u_{\alpha \beta}^{ \pm},
\end{aligned}
$$

where $\tau$ is surface residual stress and $\lambda^{s}$ and $\mu^{s}$ are the lame constants for the surface material. Plus and minus sign refer to $S^{+}$and $S^{-}$surfaces, respectively. Other essential relation for derivation of the modified differential equation is the tangential strain in terms of planar displacement component, which can be given as [47]

$$
\varepsilon_{\theta \theta}=\frac{1}{R}\left[-w+\frac{\partial u}{\partial \theta}-\frac{x}{R} \frac{\partial}{\partial \theta}\left(u+\frac{\partial w}{\partial \theta}\right)\right] .
$$

Considering inextensible deformation of the curved element at $x=0$, it can be concluded that employing the tangential strain statement by assuming the corresponding out-of-plane contractions for a curved beam at (14) and assuming the same surface properties for $S^{+}$and $S^{-}$, the stress-strain relation for the surface material can be given as

$$
\tau_{\theta \theta}^{ \pm}=\tau \pm \frac{h\left[2 \mu^{s}+\lambda^{s}(1-\nu)-\nu \tau\right]}{2 R^{2}}\left(w+\frac{\partial^{2} w}{\partial \theta^{2}}\right) .
$$

In addition, by integrating the strain components on the cross-section the resultant bending moment exerting on the cross-section of the circular curved beam can be determined as follows:

$$
M=-b \int_{-h / 2}^{h / 2} E \varepsilon_{\theta \theta} x d x+\frac{b h}{2}\left(\tau_{\theta \theta}^{+}-\tau_{\theta \theta}^{-}\right) .
$$

By employing (15) and (16) in (17) the bending moment of the cross-section can be obtained with respect to the radial displacement as follows:

$$
\begin{aligned}
& M \\
& =\left\{\frac{E I}{R^{2}}+\frac{b h^{2}\left[2 \mu^{s}+\lambda^{s}(1-\nu)-v \tau\right]}{2 R^{2}}\right\}\left(w+\frac{\partial^{2} w}{\partial \theta^{2}}\right) .
\end{aligned}
$$

Inserting (18) into (13) yields the modified governing equation of motion for the circular curved beam as a pure function of the radial displacement components, which must be solved to obtain the natural frequencies.
3.1. The Nonlocal Circular Curved Nanobeam Model. Eringen's nonlocal model states that the stress at any physical point of a body is assumed to be a function of the strain field for the whole body. The differential form of this theory is as follows [48]:

$$
\left(1-\mu \nabla^{2}\right) \sigma_{k l}=t_{k l}
$$

where $\nabla^{2}$ stands for gradient operator and $\mu$ is the nonlocality. The size effect on the response of nanostructure is taken into account by the scale length $e_{0} a$. However, the relation between nonlocality $(\mu)$ and scale length $\left(e_{0} a\right)$ can be written as follows:

$$
\mu=\left(e_{0} a\right)^{2}
$$

In one-dimensional problems, the nonlocal constitutive relations of an elastic material can be written as follows:

$$
\sigma_{x x}-\mu \frac{\partial^{2} \sigma_{x x}}{\partial x^{2}}=E \varepsilon_{x x}
$$

where $\sigma$ and $\varepsilon$ depute the nonlocal stress and strain at any point, respectively. Also, E represents Young's modulus. By integrating (19) and (20) over cross-sectional area of the beam, force-strain and moment-strain of nonlocal circular beam model will be given as

$$
M-\frac{\mu}{R^{2}} \frac{\partial^{2} M}{\partial \theta^{2}}=-\frac{D}{R^{2}}\left(w+\frac{\partial^{2} w}{\partial \theta^{2}}\right),
$$

where $D$ is defined as follows:

$$
D=E I+\frac{b h^{2}(2 \mu s+\lambda s(1-\nu)-v \tau)}{2} .
$$

By inserting (22) in (13), the governing equation is obtained as follows:

$$
\begin{aligned}
\frac{D}{R^{3}}( & \left.\frac{\partial^{6} w}{\partial \theta^{6}}+2 \frac{\partial^{4} w}{\partial \theta^{4}}+\frac{\partial^{2} w}{\partial \theta^{2}}\right)+\frac{N^{T}}{R} \frac{\partial^{4} w}{\partial \theta^{4}}-\frac{\mu}{R^{3}} N^{T} \frac{\partial^{6} w}{\partial \theta^{6}} \\
& -\frac{\partial^{2} f}{\partial \theta^{2}} R+\frac{\mu}{R} \frac{\partial^{4} f}{\partial \theta^{4}} \\
= & -\left(\rho A R+2 b R \rho^{s}\right)\left(\frac{\partial^{4} w}{\partial \theta^{2} \partial t^{2}}-\frac{\partial^{2} w}{\partial t^{2}}\right) \\
& +\frac{\mu}{R^{2}}\left(\frac{\partial^{6} w}{\partial \theta^{4} \partial t^{2}}-\frac{\partial^{4} w}{\partial \theta^{2} \partial t^{2}}\right)
\end{aligned}
$$

where $f$ is related to Winkler and Pasternak elastic foundations which is defined as

$$
f=-K_{w} w+\frac{K_{p}}{R^{2}} \frac{\partial^{2} w}{\partial \theta^{2}}
$$


(i) Vibration Equation. By employing (25) into (24), the governing equation is determined as follows:

$$
\begin{aligned}
& \frac{D}{R^{3}}\left(\frac{\partial^{6} w}{\partial \theta^{6}}+2 \frac{\partial^{4} w}{\partial \theta^{4}}+\frac{\partial^{2} w}{\partial \theta^{2}}\right)+\frac{N^{T}}{R} \frac{\partial^{4} w}{\partial \theta^{4}}-\frac{\mu}{R^{3}} N^{T} \frac{\partial^{6} w}{\partial \theta^{6}} \\
& \quad+K_{w} R \frac{\partial^{2} w}{\partial \theta^{2}}-\frac{K_{p}}{R} \frac{\partial^{4} w}{\partial \theta^{4}}-\mu \frac{K_{w}}{R} \frac{\partial^{4} w}{\partial \theta^{4}}+\mu \frac{K_{p}}{R^{3}} \frac{\partial^{6} w}{\partial \theta^{6}} \\
& =-\left(\rho A R+2 b R \rho^{s}\right)\left(\frac{\partial^{4} w}{\partial \theta^{2} \partial t^{2}}-\frac{\partial^{2} w}{\partial t^{2}}\right) \\
& \quad+\frac{\mu}{R^{2}}\left(\frac{\partial^{6} w}{\partial \theta^{4} \partial t^{2}}-\frac{\partial^{4} w}{\partial \theta^{2} \partial t^{2}}\right)
\end{aligned}
$$

(ii) Critical Buckling Load Equation

$$
\begin{gathered}
-\frac{D}{R^{3}}\left(\frac{\partial^{5} w}{\partial \theta^{5}}+\frac{\partial^{3} w}{\partial \theta^{3}}+\frac{\partial w}{\partial \theta}\right)-\frac{\partial f}{\partial \theta}+\frac{\mu}{R^{2}} \frac{\partial^{3} f}{\partial \theta^{3}} \\
+\frac{N^{T}}{R} \frac{\partial^{3} w}{\partial \theta^{3}}-\frac{\mu}{R^{3}} N^{T} \frac{\partial^{5} w}{\partial \theta^{5}}+\frac{N_{0}}{R} \frac{\partial^{3} w}{\partial \theta^{3}} \\
-\frac{\mu}{R^{3}} N_{0} \frac{\partial^{5} w}{\partial \theta^{5}}=0,
\end{gathered}
$$

where $f$ is defined in (24).

\section{Solution Method}

The nanoring or nanoarch with total central angle $\alpha$ is considered. The analytical solution for free vibration of nanoarches can be written as

$$
w(\theta, t)=W(\theta) e^{i \omega_{n} t}
$$

in which $\omega_{n}$ is the natural frequency of the nanoring. Navier solution is employed for simply-simply supported circular curved nanobeam. Therefore (27) can be rewritten as follows:

$$
w(\theta, t)=\sin \left(\frac{n \pi}{\alpha} \theta\right) e^{i \omega_{n} t}
$$

where $\sin ((n \pi / \alpha) \theta)$ is the corresponding deformation shape of the circular curved nanobeam and nanoring, and $i$ is the conventional imaginary number $\sqrt{-1}$. Substituting (29) into (26) and (27), natural frequencies and critical buckling load of the circular curved nanobeam and nanoring with surface properties and elastic foundation can be obtained.

\section{Numerical Results}

In this section, numerical results are presented for the vibration and buckling of circular curved nanobeam embedded in an elastic medium with surface properties. In the first step, the accuracy study of the present analytically method is illustrated. The bulk elastic properties are $E=177.3 \mathrm{Gpa}$, $\rho=7000 \mathrm{Kg} / \mathrm{m}^{3}$, and $\nu=0.27$, and the surface elastic properties are $\lambda^{s}=-8 \mathrm{~N} / \mathrm{m}, \mu^{s}=2.5 \mathrm{~N} / \mathrm{m}, \tau=1.7 \mathrm{~N} / \mathrm{m}$, and $\rho^{s}=7 \times 10^{-6} \mathrm{Kg} / \mathrm{m}^{2}[8]$.

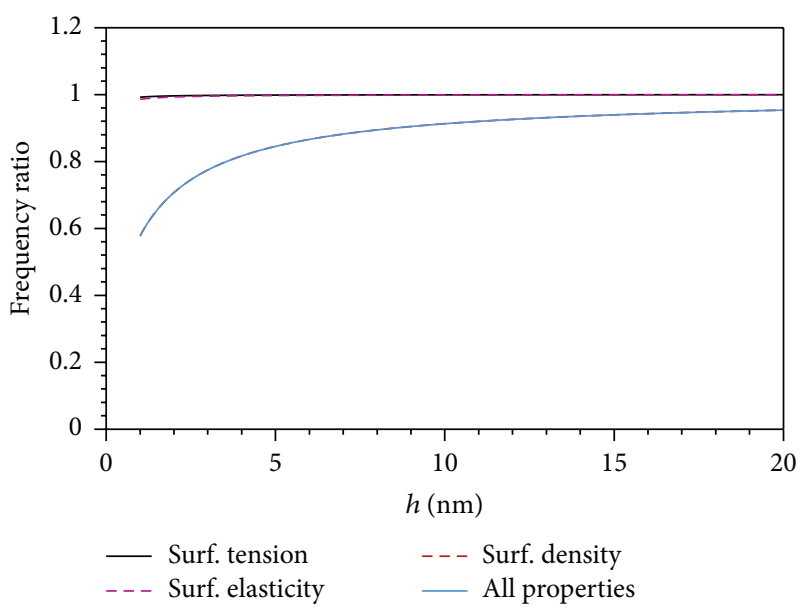

FIGURE 2: Comparison between the effect of various surface properties on natural frequency with respect to thickness $h(\mathrm{~nm})$.

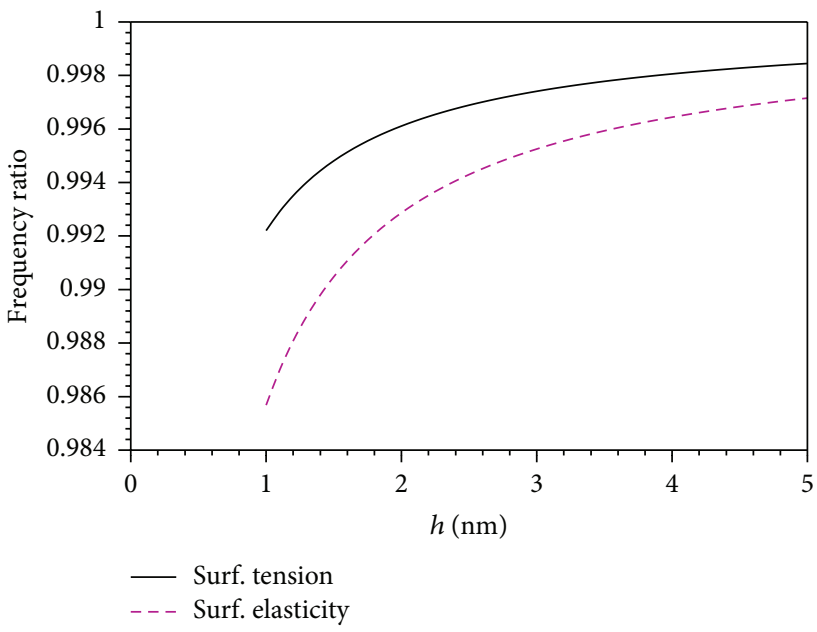

FIgURE 3: Comparison between the effect of surface tension and surface elasticity on natural frequency with respect to thickness $h(\mathrm{~nm})$.

5.1. Validation of the Results. To validate results, elastic foundations, thermal effect, and nonlocal coefficient are eliminated and simply-simply supported boundary conditions are considered. Therefore, the plot of frequency ratio versus thickness of curved nanobeam is illustrated in Figures 2 and 3. The results by comparison with [33] have been reached to reasonable results. In this survey the validity of our research can be represented as is shown in Figures 2 and 3. However, to validate results with nonlocal coefficient, the accuracy of the nonlocal natural frequencies of straight nanotube is investigated $[4,6]$. The nondimensional fundamental frequencies and critical buckling loads of the nonlocal nanotube without consideration of the surface properties are compared to the results presented by Reddy [4], Thai, [6], and Ebrahimi et al. [20] and are listed in Tables 1 and 2, respectively. It is observed that the present results agree very well with those given by $[4,6,20]$ and that increasing the nonlocality parameter tends to decrease the natural frequency and critical buckling 
TABLE 1: Comparison of the dimensionless fundamental natural frequencies of simply supported nanobeam.

\begin{tabular}{cccccc}
\hline$L / h \quad \mu$ & Thai [6] & Reddy [4] & Ebrahimi et al. [20] & Present study \\
\hline \multirow{4}{*}{10} & 0 & 9.8293 & 9.8696 & 9.8696 & 9.8696 \\
& 1 & 9.3774 & 9.4159 & 9.4159 & 9.4159 \\
& 2 & 8.9826 & 9.0195 & 9.0195 & 9.0195 \\
& 3 & 8.6338 & 8.6693 & 8.6693 & 8.6693 \\
& 4 & 8.3228 & 8.3569 & 8.3569 & 8.3569 \\
\hline & 0 & 9.8293 & 9.8696 & 9.8696 & 9.8696 \\
& 1 & 9.3774 & 9.4159 & 9.4159 & 9.4159 \\
20 & 2 & 8.9826 & 9.0195 & 9.0195 & 9.0195 \\
& 3 & 8.6338 & 8.6693 & 8.6693 & 8.6693 \\
& 4 & 8.3228 & 8.3569 & 8.3569 & 8.3569 \\
\hline & 0 & 9.8293 & 9.8696 & 9.8696 & 9.8696 \\
& 1 & 9.3774 & 9.4159 & 9.4159 & 9.4159 \\
100 & 2 & 8.9826 & 9.0195 & 9.0195 & 9.0195 \\
& 3 & 8.6338 & 8.6693 & 8.6693 & 8.6693 \\
& 4 & 8.3228 & 8.3569 & 8.3569 & 8.3569 \\
\hline
\end{tabular}

TABLE 2: Comparison of the dimensionless critical buckling load of simply supported nanobeam.

\begin{tabular}{cccccc}
\hline$L / h \mu$ & Thai [6] & Reddy [4] & Ebrahimi et al. [20] & Present study \\
\hline \multirow{4}{*}{10} & 9.8696 & 9.8696 & 9.8696 & 9.8696 \\
& 1 & 8.9830 & 8.9830 & 8.9830 & 8.9830 \\
& 2 & 8.2426 & 8.2426 & 8.2426 & 8.2426 \\
& 3 & 7.6149 & 7.6149 & 7.6149 & 7.6149 \\
& 4 & 7.0761 & 7.0761 & 7.0761 & 7.0761 \\
\hline \multirow{4}{*}{20} & 0 & 9.8696 & 9.8696 & 9.8696 & 9.8696 \\
& 1 & 8.9830 & 8.9830 & 8.9830 & 8.9830 \\
& 2 & 8.2426 & 8.2426 & 8.2426 & 8.2426 \\
& 3 & 7.6149 & 7.6149 & 7.6149 & 7.6149 \\
& 4 & 7.0761 & 7.0761 & 7.0761 & 7.0761 \\
\hline & 0 & 9.8696 & 9.8696 & 9.8696 & 9.8696 \\
100 & 1 & 8.9830 & 8.9830 & 8.9830 & 8.9830 \\
& 2 & 8.2426 & 8.2426 & 8.2426 & 8.2426 \\
& 3 & 7.6149 & 7.6149 & 7.6149 & 7.6149 \\
& 4 & 7.0761 & 7.0761 & 7.0761 & 7.0761 \\
\hline
\end{tabular}

load. The reason is that the presence of the nonlocal effect tends to decrease the stiffness of the nanostructures and hence decrease the values of natural frequencies and critical buckling loads.

5.2. The Effect of Temperature Change. To illustrate effects of temperature on vibration and buckling of circular curved nanobeams, buckling $\eta_{\text {Thermal }}$ and vibration $\xi_{\text {Thermal }}$ nondimensional thermal ratio parameters are defined as follows:

$$
\begin{aligned}
& \eta_{\text {Thermal }}=\frac{N_{\text {Thermal }}}{N_{\text {Non-thermal }}}, \\
& \xi_{\text {Thermal }}=\frac{\Omega_{\text {Thermal }}}{\Omega_{\text {Non-thermal }}},
\end{aligned}
$$

where $N_{\text {Thermal }}$ and $N_{\text {Non-thermal }}$ represent the dimensionless critical buckling load when the influence of temperature change is assumed or eliminated, respectively. Also $\Omega_{\text {Thermal }}$

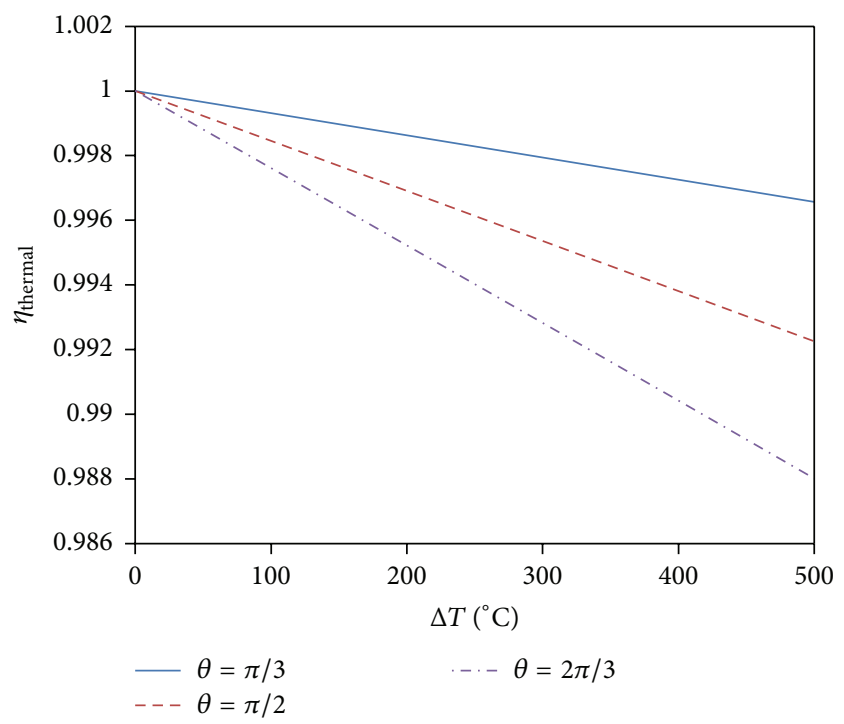

FIGURE 4: Buckling thermal ratio parameter of circular curved nanobeam with respect to temperature change $\left(\mu=1, K_{w}=\right.$ $\left.10^{10}, K_{p}=10^{-6}, R=10 \mathrm{~nm}\right)$.

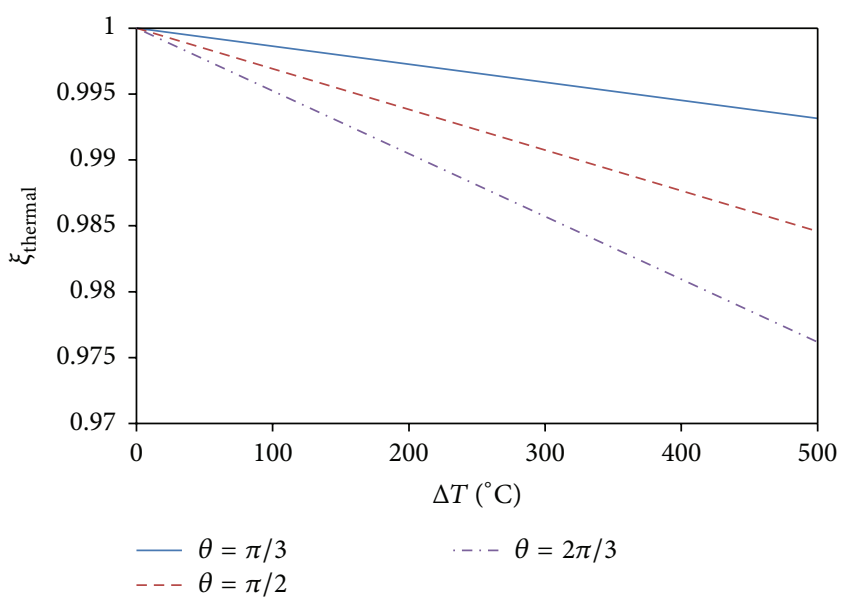

FIGURE 5: Vibration thermal ratio parameter of circular curved nanobeam with respect to temperature change $\left(\mu=1, K_{w}=\right.$ $\left.10^{10}, K_{p}=10^{-6}, R=10 \mathrm{~nm}\right)$.

and $\Omega_{\text {Non-thermal }}$ represent the dimensionless natural frequency when the effect of temperature change is considered or neglected, respectively.

As it is clear in Figures 4 and 5, for all types of opening angles considered, the vibration and critical buckling load thermal ratios $\eta_{\text {Thermal }}$ and $\xi_{\text {Thermal }}$ reduce with increasing the temperature change. In other words, with increasing of the temperature, the nondimensional natural frequency and critical buckling load reduce. Furthermore, the slope of vibration and buckling thermal ratio versus temperature change increases as the opening angles become greater.

5.3. Influence of the Nonlocal Parameter. Next, In order to illustrate the effect of the nonlocal parameter on the circular curved nanobeam in thermal environment, the 
TABLE 3: Comparison of the dimensionless fundamental natural frequencies of circular curved nanobeam with and without surface effects with various temperature changes and nonlocality $R=20 \mathrm{~nm}, K_{w}=10^{10}$, and $K_{p}=10^{-6}$.

\begin{tabular}{|c|c|c|c|c|c|c|c|}
\hline \multirow[b]{2}{*}{$\Delta T$} & \multicolumn{3}{|c|}{$\theta=\pi / 3$} & \multicolumn{2}{|c|}{$\theta=\pi / 2$} & \multicolumn{2}{|c|}{$\theta=2 \pi / 3$} \\
\hline & $\mu$ & $\begin{array}{l}\text { With surface } \\
\text { effects }\end{array}$ & $\begin{array}{c}\text { Without surface } \\
\text { effects }\end{array}$ & $\begin{array}{l}\text { With surface } \\
\text { effects }\end{array}$ & $\begin{array}{c}\text { Without surface } \\
\text { effects }\end{array}$ & $\begin{array}{l}\text { With surface } \\
\text { effects }\end{array}$ & $\begin{array}{c}\text { Without surface } \\
\text { effects }\end{array}$ \\
\hline \multirow{5}{*}{0} & 0 & 9.6217 & 11.4112 & 12.3122 & 14.5812 & 16.5025 & 19.5307 \\
\hline & 1 & 9.3899 & 11.1352 & 12.1984 & 14.4455 & 16.4623 & 19.4828 \\
\hline & 2 & 9.1919 & 10.8994 & 12.1026 & 14.3312 & 16.4287 & 19.4426 \\
\hline & 3 & 9.0207 & 10.6954 & 12.0208 & 14.2337 & 16.4002 & 19.4086 \\
\hline & 4 & 8.8710 & 10.5171 & 11.9501 & 14.1493 & 16.3756 & 19.3793 \\
\hline \multirow{5}{*}{250} & 0 & 9.5838 & 11.3666 & 12.2531 & 14.5113 & 16.4347 & 19.4504 \\
\hline & 1 & 9.3512 & 11.0865 & 12.1388 & 14.3750 & 16.3943 & 19.4023 \\
\hline & 2 & 9.1523 & 10.8527 & 12.0425 & 14.2601 & 16.3606 & 19.3620 \\
\hline & 3 & 8.9803 & 10.6478 & 11.9602 & 14.1621 & 16.3319 & 19.3278 \\
\hline & 4 & 8.8300 & 10.4687 & 11.8892 & 14.0773 & 16.3073 & 19.2984 \\
\hline \multirow{5}{*}{500} & 0 & 9.5459 & 11.3218 & 12.1937 & 14.4411 & 16.3665 & 19.3699 \\
\hline & 1 & 9.3123 & 11.0436 & 12.0788 & 14.3041 & 16.3261 & 19.3216 \\
\hline & 2 & 9.1126 & 10.8057 & 11.9820 & 14.1887 & 16.2922 & 19.2811 \\
\hline & 3 & 8.9398 & 10.5999 & 11.8994 & 14.0901 & 16.2634 & 19.2468 \\
\hline & 4 & 8.7888 & 10.4200 & 11.8280 & 14.0049 & 16.2386 & 19.2172 \\
\hline
\end{tabular}

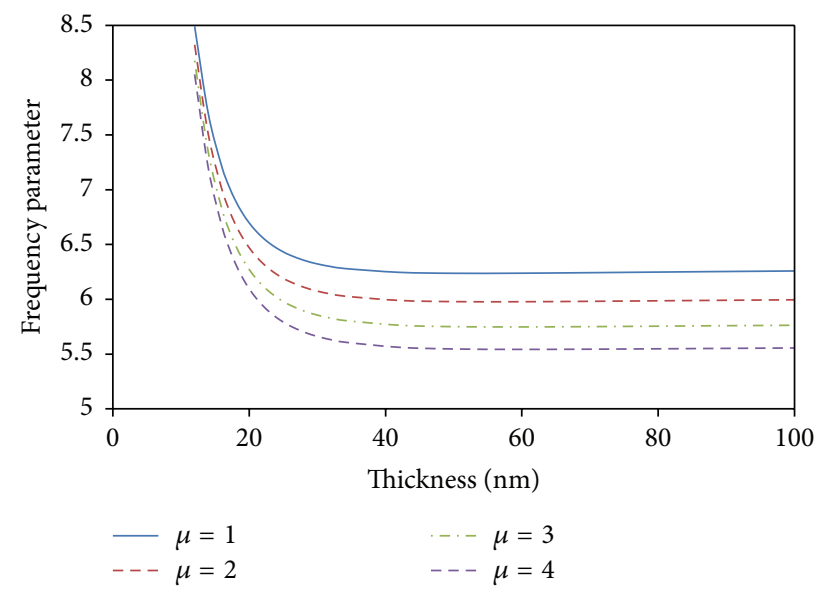

FIGURE 6: Dimensionless natural frequency with respect to thickness $h$ for various nonlocalities $\left(K_{w}=10^{10}, K_{p}=10^{-6}, R=\right.$ $30 \mathrm{~nm}, \Delta T=100)$.

nondimensional fundamental natural frequency and critical buckling load for various values of nonlocal parameters are illustrated in Figures 6 and 7. It is obviously seen from Figures 6 and 7 that the critical buckling load and frequency parameter decrease with the increase of values of the nonlocal parameter.

The reason is that the presence of the nonlocal effect tends to decrease the stiffness of the nanostructures and furthermore decrease the values of dimensionless natural frequencies and critical buckling loads.

5.4. The Effect of Surface Properties. To illustrate surface effects in thermal environment for vibration and buckling

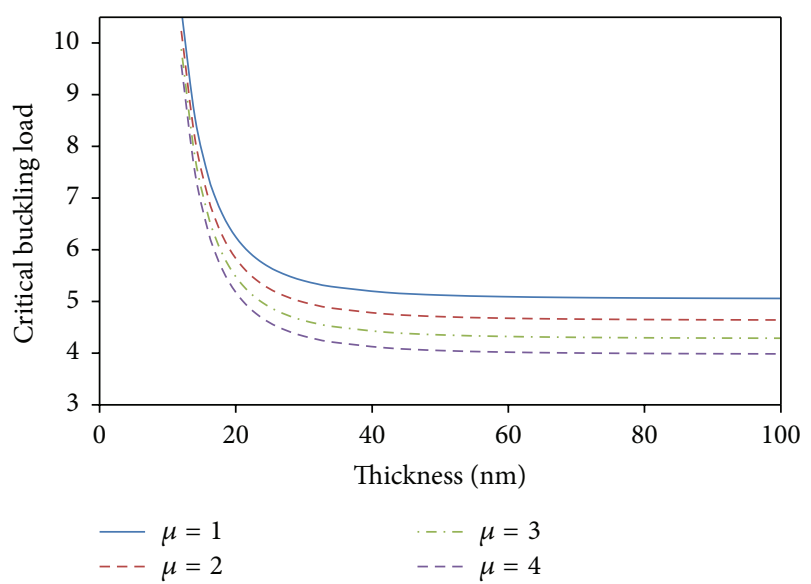

FIGURE 7: Dimensionless critical buckling load with respect to thickness $h$ for various nonlocalities $\left(K_{w}=10^{10}, K_{p}=10^{-6}, R=\right.$ $30 \mathrm{~nm}, \Delta T=100)$.

of circular curved nanobeams, Tables 3 and 4 are presented. According to the tables, the dimensionless frequency and critical buckling loads are investigated for different values of temperature changes and nonlocality with various opening angles, with and without surface properties.

According to Tables 3 and 4, it is obviously seen that the dimensionless frequency and critical buckling load decrease with considering surface properties and also decrease when opening angle increases. It is interesting to say that natural frequencies and critical buckling load also decrease with increase in temperature changes. However, to compare Table 3 with Table 4 it can be seen that surface properties are more sensitive in vibration analysis than buckling analysis. 
TABLE 4: Comparison of the dimensionless critical buckling loads of circular curved nanobeam with and without surface effects with various temperature changes and nonlocality $R=20 \mathrm{~nm}, K_{w}=10^{10}$, and $K_{p}=10^{-6}$.

\begin{tabular}{|c|c|c|c|c|c|c|c|}
\hline \multirow[b]{2}{*}{$\Delta T$} & \multicolumn{3}{|c|}{$\theta=\pi / 3$} & \multicolumn{2}{|c|}{$\theta=\pi / 2$} & \multicolumn{2}{|c|}{$\theta=2 \pi / 3$} \\
\hline & $\mu$ & $\begin{array}{l}\text { With surface } \\
\text { effects }\end{array}$ & $\begin{array}{c}\text { Without surface } \\
\text { effects }\end{array}$ & $\begin{array}{l}\text { With surface } \\
\text { effects }\end{array}$ & $\begin{array}{c}\text { Without surface } \\
\text { effects }\end{array}$ & $\begin{array}{l}\text { With surface } \\
\text { effects }\end{array}$ & $\begin{array}{c}\text { Without surface } \\
\text { effects }\end{array}$ \\
\hline \multirow{5}{*}{0} & 0 & 14.5910 & 14.6596 & 26.8786 & 26.9274 & 55.7991 & 55.8259 \\
\hline & 1 & 13.8967 & 13.9591 & 26.3843 & 26.4287 & 55.5279 & 55.5523 \\
\hline & 2 & 13.3168 & 13.3740 & 25.9715 & 26.0122 & 55.3014 & 55.3237 \\
\hline & 3 & 12.8252 & 12.8781 & 25.6215 & 25.6592 & 55.1094 & 55.1300 \\
\hline & 4 & 12.4032 & 12.4523 & 25.3211 & 25.3561 & 54.9445 & 54.9637 \\
\hline \multirow{5}{*}{250} & 0 & 14.4766 & 14.5451 & 26.6212 & 26.6700 & 55.3414 & 55.3682 \\
\hline & 1 & 13.7822 & 13.8446 & 26.1268 & 26.1713 & 55.0702 & 55.0946 \\
\hline & 2 & 13.2023 & 13.2596 & 25.7140 & 25.7548 & 54.8437 & 54.8660 \\
\hline & 3 & 12.7108 & 12.7637 & 25.3641 & 25.4017 & 54.6516 & 54.6723 \\
\hline & 4 & 12.2888 & 12.3379 & 25.0636 & 25.0986 & 54.4868 & 54.5060 \\
\hline \multirow{5}{*}{500} & 0 & 14.3622 & 14.4307 & 26.3637 & 26.4125 & 54.8837 & 54.9105 \\
\hline & 1 & 13.6678 & 13.7302 & 25.8694 & 25.9138 & 54.6125 & 54.6368 \\
\hline & 2 & 13.0879 & 13.1452 & 25.4565 & 25.4973 & 54.3859 & 54.4083 \\
\hline & 3 & 12.5963 & 12.6492 & 25.1066 & 25.1442 & 54.1939 & 54.2146 \\
\hline & 4 & 12.1743 & 12.2235 & 24.8062 & 24.8412 & 54.0291 & 54.0483 \\
\hline
\end{tabular}

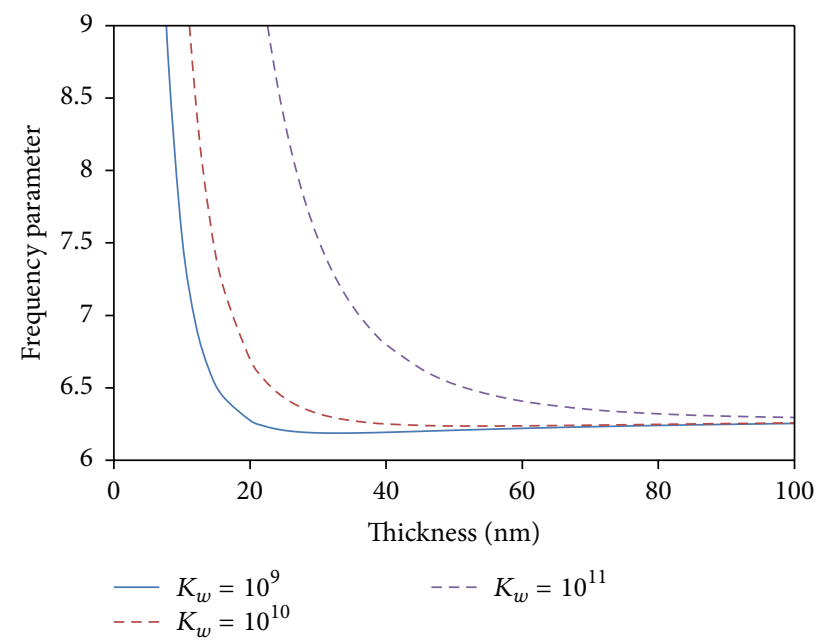

Figure 8: Dimensionless natural frequency with respect to thickness $h$ for various Winkler elastic foundations $\left(K_{p}=10^{-6}, R=\right.$ $30 \mathrm{~nm}, \Delta T=100, \mu=1, b=50 \mathrm{~nm}, \theta=\pi / 2)$.

The results in Tables 3 and 4 can be used for design of circular curved nanobeams and nanorings in future.

\section{Influence of the Winkler and Pasternak Elastic Foundations}

In order to investigate the influence of the elastic foundation surrounding the circular curved nanobeam in thermal environment, the nondimensional fundamental natural frequency and critical buckling load for various values of Winkler and Pasternak parameters are illustrated in Figures $8,9,10$, and 11 . It can be observed that the nondimensional

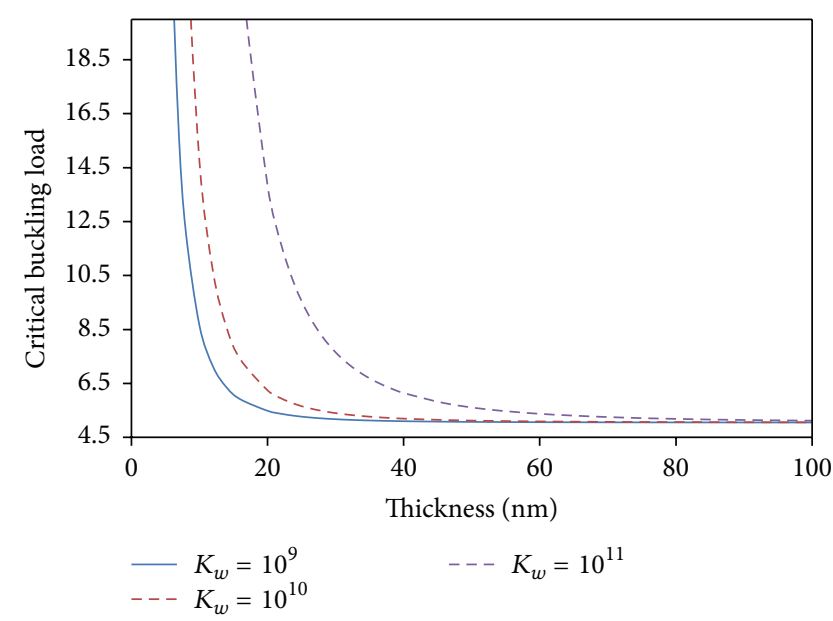

FIGURE 9: Dimensionless critical buckling load with respect to thickness $h$ for various Winkler elastic foundations $\left(K_{p}=10^{-6}, R=\right.$ $30 \mathrm{~nm}, \Delta T=100, \mu=1, b=50 \mathrm{~nm}, \theta=\pi / 2)$.

natural frequency and critical buckling load increase when the Winkler elastic foundation becomes stiffer. It is also seen that the influence of thickness on the nondimensional natural frequency and critical buckling load is higher than the Winkle parameter.

The nondimensional natural frequency and critical buckling load as a function of thickness, for three different Pasternak elastic foundation values, are illustrated in Figures 9 and 10 , respectively. It can be observed that the nondimensional natural frequency and critical buckling load increase when the Pasternak elastic foundation becomes greater. It is also seen that the effect of thickness on the nondimensional 


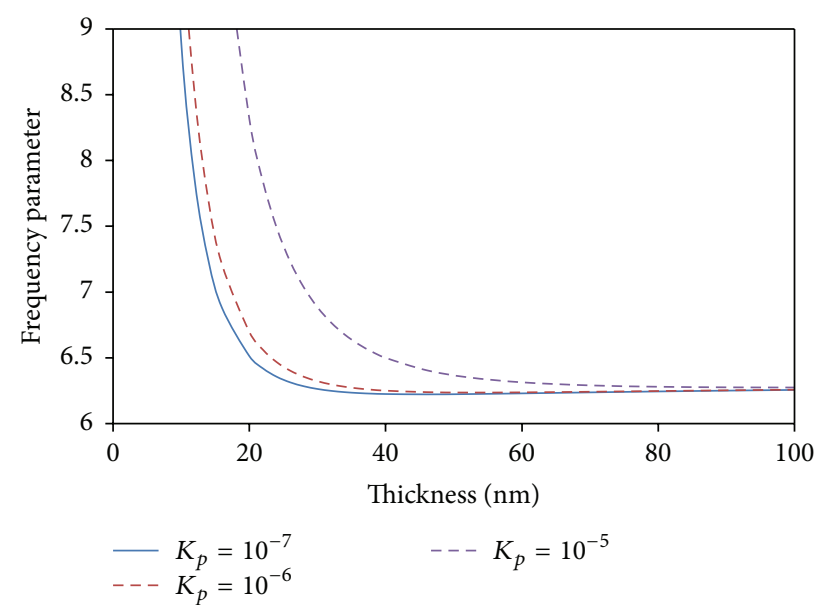

FIGURE 10: Dimensionless natural frequency with respect to thickness $h$ for various Pasternak elastic foundations $\left(K_{w}=10^{10}, R=\right.$ $30 \mathrm{~nm}, \Delta T=100, \mu=1, b=50 \mathrm{~nm}, \theta=\pi / 2)$.

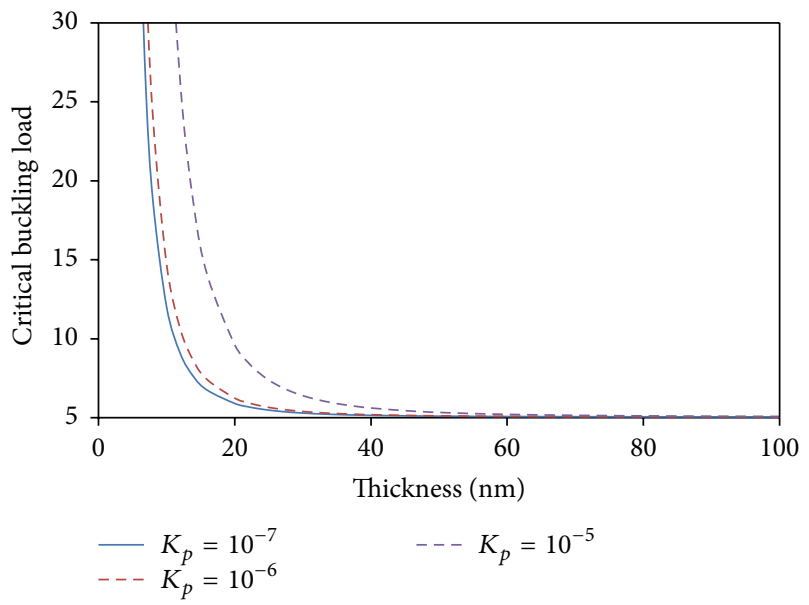

FIGURE 11: Dimensionless critical buckling load with respect to thickness $h$ for various Pasternak elastic foundations $\left(K_{w}=\right.$ $\left.10^{10}, R=30 \mathrm{~nm}, \Delta T=100, \mu=1, b=50 \mathrm{~nm}, \theta=\pi / 2\right)$.

natural frequency and critical buckling load is higher than the Pasternak parameter. Moreover, by comparing Figures 7 and 8 with Figures 9 and 10, it should be noted that the influence of the Pasternak elastic foundation on the nondimensional natural frequency and critical buckling load is higher than the effect of the Winkler elastic foundation.

\section{Conclusion}

In this research, the surface properties on dimensionless natural frequency and critical buckling load of circular curved nanobeam embedded in an elastic medium were studied with various opening angles in the thermal environment, using the nonlocal elasticity model. Hamilton's principle was employed to derive the governing equations. Next, the analytically exact solution was employed to solve the governing equations for simply supported curved nanobeam. The effects of the surface properties, thickness of circular curved nanobeam, Winkler and Pasternak elastic foundations, opening angle, temperature changes, and nonlocal parameter were investigated on the frequency and critical buckling load parameters of the circular curved nanobeams. It is clearly observed that, by increasing thickness $h$, the surface effects tend to vanish. Furthermore it is shown that natural frequencies and critical buckling load also decrease with increase in temperature changes. In addition, results revealed that the elastic foundations and surface properties play an important role in vibration and buckling behavior of circular curved nanobeams. However it is interesting to say that the surface properties are more sensitive in vibration analysis than buckling analysis.

\section{Competing Interests}

The authors declare that there is no conflict of interests regarding the publication of this article.

\section{References}

[1] M. Şimșek, "Large amplitude free vibration of nanobeams with various boundary conditions based on the nonlocal elasticity theory," Composites Part B: Engineering, vol. 56, pp. 621-628, 2014.

[2] B. Hu, Y. Ding, W. Chen et al., "External-strain induced insulating phase transition in $\mathrm{VO}_{2}$ nanobeam and its application as flexible strain sensor," Advanced Materials, vol. 22, no. 45, pp. 5134-5139, 2010.

[3] T. L. Daulton, K. S. Bondi, and K. F. Kelton, "Nanobeam diffraction fluctuation electron microscopy technique for structural characterization of disordered materials-application to $\mathrm{Al}_{88-\mathrm{x}} \mathrm{Y}_{7} \mathrm{Fe}_{5} \mathrm{Ti}_{\mathrm{x}}$ metallic glasses," Ultramicroscopy, vol. 110, no. 10, pp. 1279-1289, 2010.

[4] J. N. Reddy, "Nonlocal theories for bending, buckling and vibration of beams," International Journal of Engineering Science, vol. 45, no. 2-8, pp. 288-307, 2007.

[5] Ç. Demir and Ö. Civalek, "Torsional and longitudinal frequency and wave response of microtubules based on the nonlocal continuum and nonlocal discrete models," Applied Mathematical Modelling, vol. 37, no. 22, pp. 9355-9367, 2013.

[6] H.-T. Thai, "A nonlocal beam theory for bending, buckling, and vibration of nanobeams," International Journal of Engineering Science, vol. 52, pp. 56-64, 2012.

[7] L.-L. Ke, Y.-S. Wang, and Z.-D. Wang, "Nonlinear vibration of the piezoelectric nanobeams based on the nonlocal theory," Composite Structures, vol. 94, no. 6, pp. 2038-2047, 2012.

[8] T. Murmu and S. Adhikari, "Nonlocal transverse vibration of double-nanobeam-systems," Journal of Applied Physics, vol. 108, no. 8, Article ID 083514, 2010.

[9] M. A. Eltaher, S. A. Emam, and F. F. Mahmoud, "Free vibration analysis of functionally graded size-dependent nanobeams," Applied Mathematics and Computation, vol. 218, no. 14, pp. 7406-7420, 2012.

[10] M. E. Gurtin and A. I. Murdoch, "Surface stress in solids," International Journal of Solids and Structures, vol. 14, no. 6, pp. 431-440, 1978.

[11] M. Shaat, F. F. Mahmoud, X.-L. Gao, and A. F. Faheem, "Sizedependent bending analysis of Kirchhoff nano-plates based 
on a modified couple-stress theory including surface effects," International Journal of Mechanical Sciences, vol. 79, pp. 31-37, 2014.

[12] X. Liang, S. Hu, and S. Shen, "Surface effects on the post-buckling of piezoelectric nanowires," Physica E: LowDimensional Systems and Nanostructures, vol. 69, pp. 61-64, 2015.

[13] S. A. H. Hosseini and O. Rahmani, "Free vibration of shallow and deep curved FG nanobeam via nonlocal Timoshenko curved beam model," Applied Physics A, vol. 122, article 169, 2016.

[14] B. Gheshlaghi and S. M. Hasheminejad, "Surface effects on nonlinear free vibration of nanobeams," Composites Part B: Engineering, vol. 42, no. 4, pp. 934-937, 2011.

[15] P. A. Sharabiani and M. R. H. Yazdi, "Nonlinear free vibrations of functionally graded nanobeams with surface effects," Composites Part B: Engineering, vol. 45, no. 1, pp. 581-586, 2013.

[16] R. Nazemnezhad, M. Salimi, S. H. Hashemi, and P. A. Sharabiani, "An analytical study on the nonlinear free vibration of nanoscale beams incorporating surface density effects," Composites Part B: Engineering, vol. 43, no. 8, pp. 2893-2897, 2012.

[17] S. Hosseini-Hashemi and R. Nazemnezhad, "An analytical study on the nonlinear free vibration of functionally graded nanobeams incorporating surface effects," Composites Part B: Engineering, vol. 52, pp. 199-206, 2013.

[18] R. Ansari, V. Mohammadi, M. Faghih Shojaei, R. Gholami, and S. Sahmani, "On the forced vibration analysis of Timoshenko nanobeams based on the surface stress elasticity theory," Composites Part B: Engineering, vol. 60, pp. 158-166, 2014.

[19] P. Malekzadeh and M. Shojaee, "Surface and nonlocal effects on the nonlinear free vibration of non-uniform nanobeams," Composites Part B: Engineering, vol. 52, pp. 84-92, 2013.

[20] F. Ebrahimi, G. R. Shaghaghi, and M. Boreiry, "A semi-analytical evaluation of surface and nonlocal effects on buckling and vibrational characteristics of nanotubes with various boundary conditions," International Journal of Structural Stability and Dynamics, vol. 16, no. 6, 20 pages, 2016.

[21] T. Zhao, J. Luo, and Z. Xiao, "Buckling analysis of a nanowire lying on Winkler-Pasternak elastic foundation," Mechanics of Advanced Materials and Structures, vol. 22, no. 5, pp. 394-401, 2015.

[22] A. Fallah and M. M. Aghdam, "Nonlinear free vibration and post-buckling analysis of functionally graded beams on nonlinear elastic foundation," European Journal of MechanicsA/Solids, vol. 30, no. 4, pp. 571-583, 2011.

[23] T. S. Jang, H. S. Baek, and J. K. Paik, "A new method for the nonlinear deflection analysis of an infinite beam resting on a nonlinear elastic foundation," International Journal of Non-Linear Mechanics, vol. 46, no. 1, pp. 339-346, 2011.

[24] H. Niknam and M. M. Aghdam, "A semi analytical approach for large amplitude free vibration and buckling of nonlocal FG beams resting on elastic foundation," Composite Structures, vol. 119, pp. 452-462, 2015.

[25] H. Mohammadi, M. Mahzoon, M. Mohammadi, and M. Mohammadi, "Postbuckling instability of nonlinear nanobeam with geometric imperfection embedded in elastic foundation," Nonlinear Dynamics, vol. 76, no. 4, pp. 2005-2016, 2014.

[26] S. C. Pradhan and G. K. Reddy, "Buckling analysis of single walled carbon nanotube on Winkler foundation using nonlocal elasticity theory and DTM," Computational Materials Science, vol. 50, no. 3, pp. 1052-1056, 2011.
[27] C. M. Wang and W. H. Duan, "Free vibration of nanorings/arches based on nonlocal elasticity," Journal of Applied Physics, vol. 104, no. 1, Article ID 014303, 2008.

[28] P. Malekzadeh, M. R. G. Haghighi, and M. M. Atashi, "Outof-plane free vibration of functionally graded circular curved beams in thermal environment," Composite Structures, vol. 92, no. 2, pp. 541-552, 2010.

[29] Z. Yan and L. Jiang, "Electromechanical response of a curved piezoelectric nanobeam with the consideration of surface effects," Journal of Physics D: Applied Physics, vol. 44, no. 36, Article ID 365301, 2011.

[30] H. Kananipour, M. Ahmadi, and H. Chavoshi, "Application of nonlocal elasticity and DQM to dynamic analysis of curved nanobeams," Latin American Journal of Solids and Structures, vol. 11, no. 5, pp. 848-853, 2014.

[31] M. Khater, M. Eltaher, E. Abdel-Rahman, and M. Yavuz, "Surface and thermal load effects on the buckling of curved nanowires," Engineering Science and Technology, vol. 17, no. 4, pp. 279-283, 2014.

[32] A. Setoodeh, M. Derahaki, and N. Bavi, "DQ thermal buckling analysis of embedded curved carbon nanotubes based on nonlocal elasticity theory," Latin American Journal of Solids and Structures, vol. 12, no. 10, pp. 1901-1917, 2015.

[33] A. Assadi and B. Farshi, "Size dependent vibration of curved nanobeams and rings including surface energies," Physica E: Low-Dimensional Systems and Nanostructures, vol. 43, no. 4, pp. 975-978, 2011.

[34] Q. Wan, Q. H. Li, Y. J. Chen et al., "Fabrication and ethanol sensing characteristics of $\mathrm{ZnO}$ nanowire gas sensors," Applied Physics Letters, vol. 84, no. 18, pp. 3654-3656, 2004.

[35] J.-Y. Juang, D. B. Bogy, and C. S. Bhatia, "Design and dynamics of flying height control slider with piezoelectric nanoactuator in hard disk drives," Journal of Tribology, vol. 129, no. 1, pp. 161-170, 2007.

[36] T. Ye, G. Jin, X. Ye, and X. Wang, "A series solution for the vibrations of composite laminated deep curved beams with general boundaries," Composite Structures, vol.127, pp. 450-465, 2015.

[37] F. Ebrahimi and E. Salari, "A semi-analytical method for vibrational and buckling analysis of functionally graded nanobeams considering the physical neutral axis position," Computer Modeling in Engineering and Sciences, vol. 105, no. 2, pp. 151-181, 2015.

[38] F. Ebrahimi and M. R. Barati, "Dynamic modeling of a thermopiezo-electrically actuated nanosize beam subjected to a magnetic field," Applied Physics A, vol. 122, no. 4, pp. 1-18, 2016.

[39] F. Ebrahimi and M. R. Barati, "Vibration analysis of smart piezoelectrically actuated nanobeams subjected to magnetoelectrical field in thermal environment," Journal of Vibration and Control, 2016.

[40] F. Ebrahimi and M. R. Barati, "Buckling analysis of smart size-dependent higher order magneto-electro-thermo-elastic functionally graded nanosize beams," Journal of Mechanics, 2016.

[41] F. Ebrahimi and M. R. Barati, "Electromechanical buckling behavior of smart piezoelectrically actuated higher-order sizedependent graded nanoscale beams in thermal environment," International Journal of Smart and Nano Materials, vol. 7, no. 2, pp. 69-90, 2016.

[42] F. Ebrahimi and M. R. Barati, "Small scale effects on hygrothermo-mechanical vibration of temperature dependent nonhomogeneous nanoscale beams," Mechanics of Advanced Materials and Structures, 2016. 
[43] F. Ebrahimi and M. R. Barati, "A nonlocal higher-order shear deformation beam theory for vibration analysis of sizedependent functionally graded nanobeams," Arabian Journal for Science and Engineering, vol. 41, no. 5, pp. 1679-1690, 2016.

[44] F. Ebrahimi and E. Salari, "Effect of various thermal loadings on buckling and vibrational characteristics of nonlocal temperature-dependent functionally graded nanobeams," Mechanics of Advanced Materials and Structures, vol. 23, no. 12, pp. 1379-1397, 2016.

[45] F. Ebrahimi and E. Salari, "Thermo-mechanical vibration analysis of nonlocal temperature-dependent FG nanobeams with various boundary conditions," Composites Part B: Engineering, vol. 78, pp. 272-290, 2015.

[46] F. Ebrahimi, E. Salari, and S. A. H. Hosseini, “Thermomechanical vibration behavior of FG nanobeams subjected to linear and non-linear temperature distributions," Journal of Thermal Stresses, vol. 38, no. 12, pp. 1360-1386, 2015.

[47] S. S. Rao, Vibration of Continuous Systems, John Wiley \& Sons, New York, NY, USA, 2007.

[48] A. C. Eringen, "On differential equations of nonlocal elasticity and solutions of screw dislocation and surface waves," Journal of Applied Physics, vol. 54, no. 9, pp. 4703-4710, 1983. 


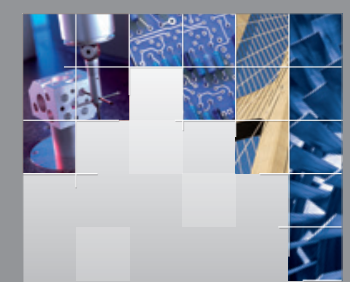

\section{Enfincering}
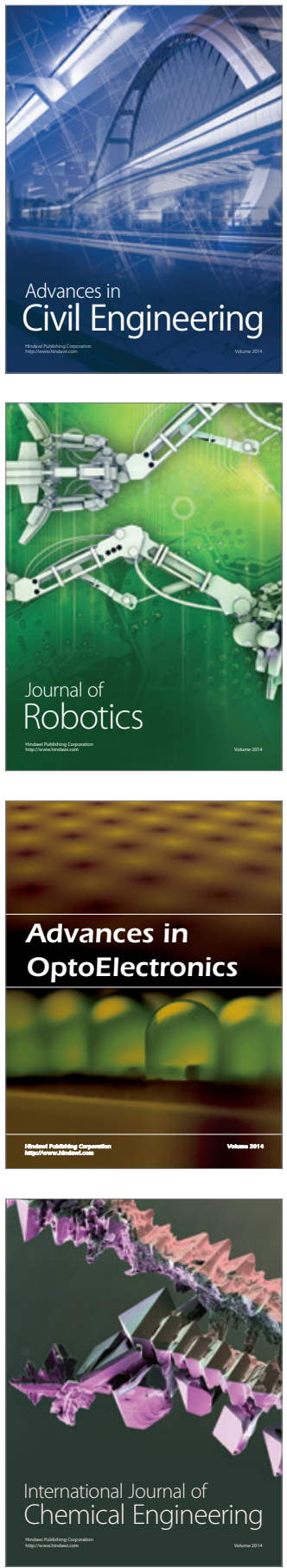

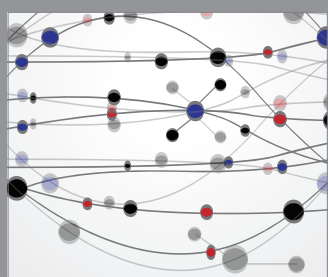

The Scientific World Journal

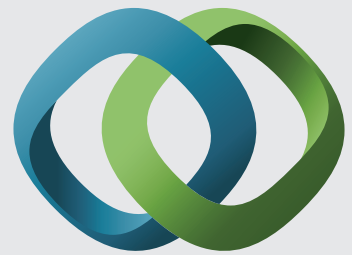

\section{Hindawi}

Submit your manuscripts at

http://www.hindawi.com
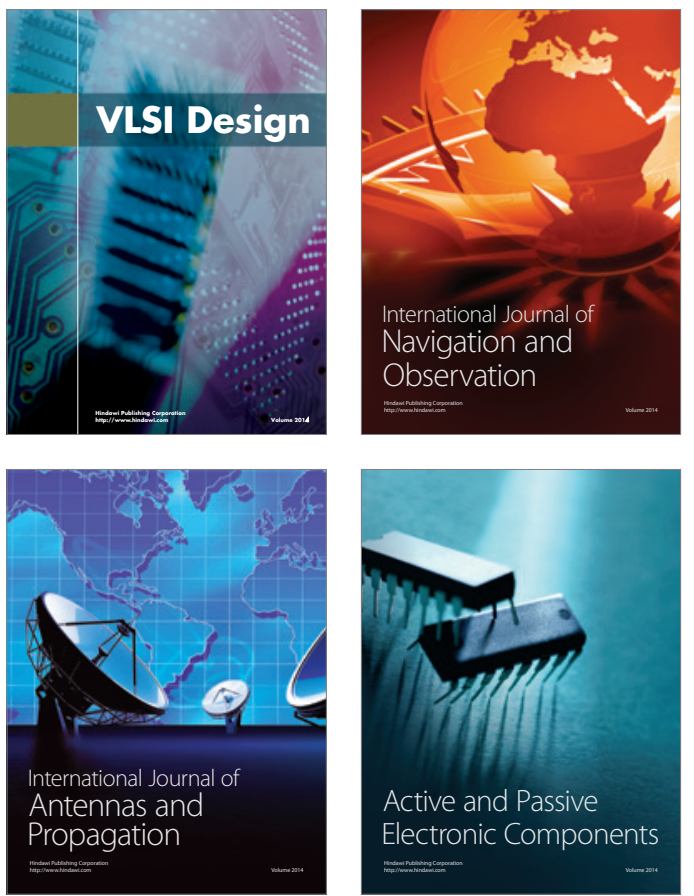
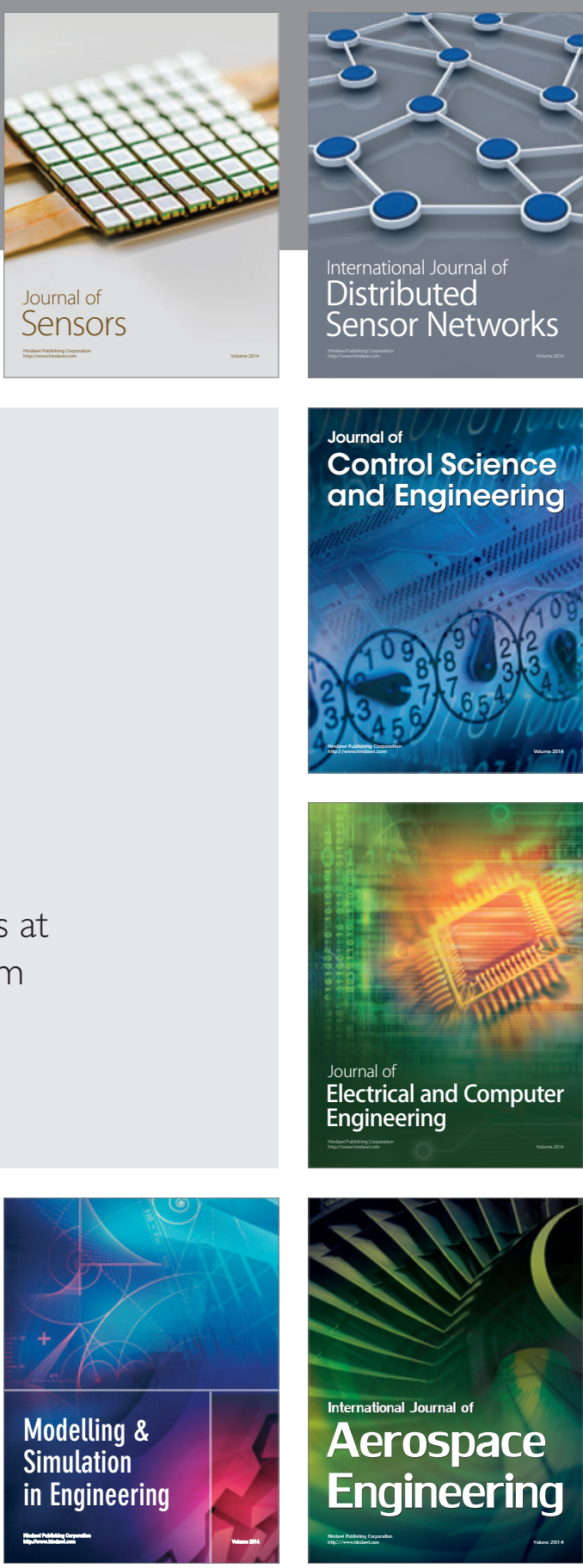

International Journal of

Distributed

Sensor Networks

Journal of

Control Science

and Engineering
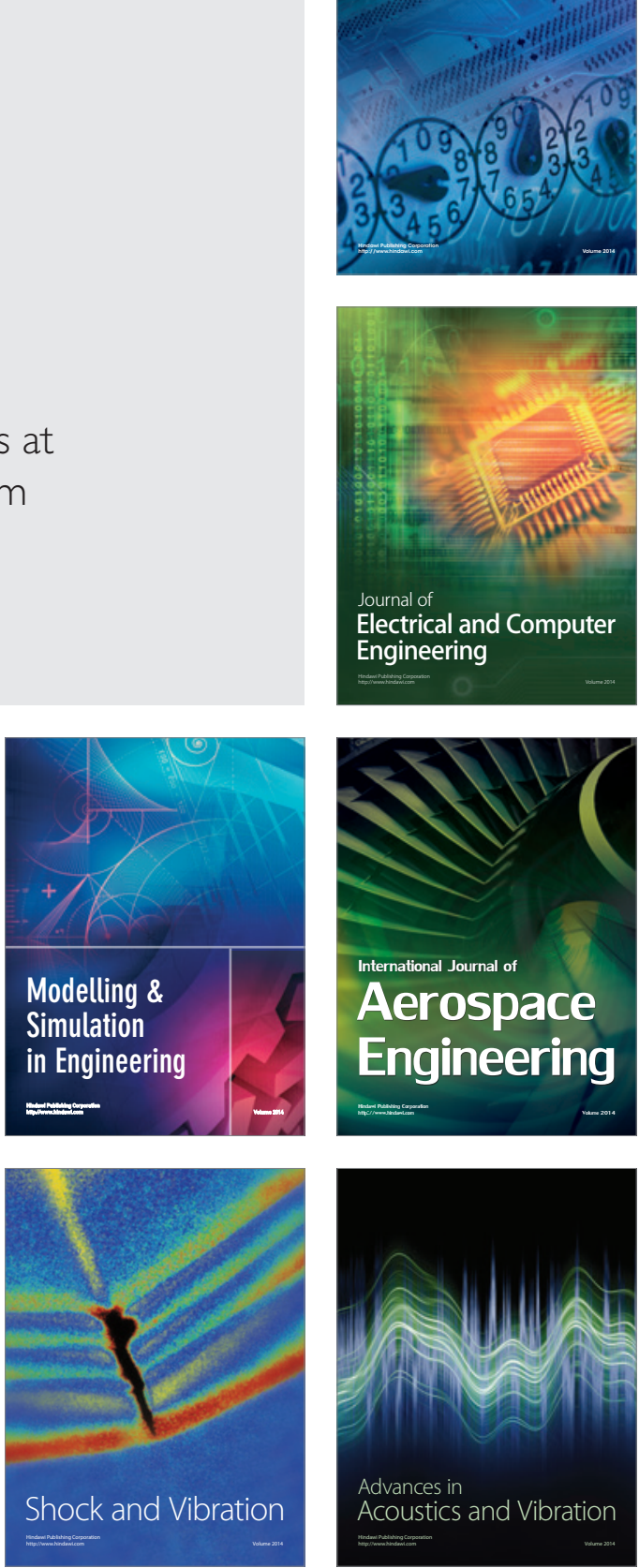